Fabian Jenderek

\title{
Die arbeitsrechtliche Stellung geschäftsführender Organmitglieder im Internationalen Privatrecht
}

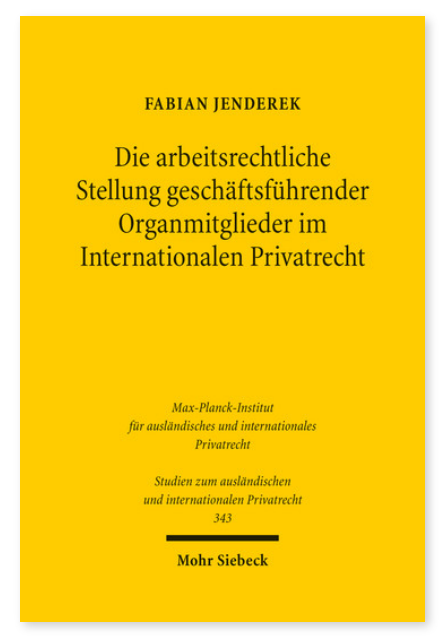

2015. XXIX, 210 Seiten. StudIPR 343

ISBN 978-3-16-153700-4

DOI 10.1628/978-3-16-153700-4

eBook PDF 74,00€

ISBN 978-3-16-153699-1

fadengeheftete Broschur 74,00€
Die Anwendung von Arbeitsrecht auf geschäftsführende Organmitglieder ist bereits im nationalen Recht Gegenstand kontroverser Diskussionen. Weist das Verhältnis zwischen Gesellschaft und Organmitglied einen Auslandsbezug auf, etwa durch den Sitz oder das Gründungsrecht der Gesellschaft, stellen sich ähnliche Fragen auf der Ebene des Internationalen Privatrechts. Hier zeigt sich, dass nicht jedem Sachverhalt von vornherein die deutsche Sichtweise einer strikten Trennung von arbeits-/dienstvertraglichem Anstellungs- und gesellschaftsrechtlichem Bestellungsverhältnis zugrunde gelegt werden kann. Ein Vergleich mit dem englischen und französischen Recht verdeutlicht die Notwendigkeit der Berücksichtigung anderer Rechtsordnungen. Neben allgemeinen kollisionsrechtlichen Aspekten werden bei der Untersuchung insbesondere die unionsrechtlichen Anforderungen an einen Individualarbeitsvertrag relevant.

Fabian Jenderek Geboren 1983; Studium der Rechtswissenschaften an der Universität Freiburg; 2009-11 Wissenschaftlicher Mitarbeiter an der Universität Freiburg; Referendariat in Düsseldorf; 2013 Promotion; seit 2013 Rechtsanwalt in Düsseldorf.

Jetzt bestellen:

https://mohrsiebeck.com/buch/die-arbeitsrechtliche-stellung-geschaeftsfuehrender-organmitglieder-im-internationalenprivatrecht-9783161537004?no_cache=1

order@mohrsiebeck.com

Telefon: +49 (0)7071-923-17

Telefax: $+49(0) 7071-51104$ 